\title{
Educação Superior em tempos de pandemia: a experiência do Núcleo de Apoio a Tecnologias Educacionais da Universidade
}

\section{Federal de Pelotas}

\author{
Carla Michele Rech ${ }^{1}$ \\ Jonas Rodeghiero ${ }^{2}$ \\ Christiano Martino Otero Avila ${ }^{3}$ \\ Rosaura Espírito Santo da Silva ${ }^{4}$ \\ Maria de Fátima Cóssio ${ }^{5}$
}

\section{RESUMO}

Com a pandemia do novo coronavírus e a interrupção das atividades presenciais em praticamente todo o mundo, na área da Educação, as universidades tiveram que se adaptar para dar continuidade às suas ações. Apesar das aulas terem sido suspensas em março de 2020 na UFPEL, essa interrupção não se estendeu por muito tempo. Buscando reduzir os danos pedagógicos, a instituição tomou uma série de medidas para garantir a manutenção de uma educação de qualidade e segura, o que incluiu a criação do Núcleo de Apoio a Tecnologias Educacionais (NATE). $O$ presente artigo tem por objetivo relatar a experiência do NATE e compartilhar as práticas que foram desenvolvidas no sentido de apoiar a adoção do Ensino Remoto Emergencial na universidade

Palavras-chave: Pandemia. Ensino Remoto Emergencial. Apoio Educacional. Tecnologias. Experiência.

\footnotetext{
${ }^{1}$ carlatsul@yahoo.com.br - Universidade Federal de Pelotas

${ }^{2}$ eurodeghiero@gmail.com - Universidade Federal de Pelotas

${ }^{3}$ christiano.avila@ufpel.edu.br - Universidade Federal de Pelotas

4 rosaura.silva@ufpel.edu.br - Universidade Federal de Pelotas

${ }^{5}$ mfcossio@ufpel.edu.br - Universidade Federal de Pelotas
} 
University education in times of pandemic: The experience of the Support Center for Educational Technologies at the Federal University of Pelotas

\section{ABSTRACT}

With the coronavirus pandemic and the interruption of face-to-face activities practically all over the world, among them activities related to education, universities had to adapt to continue their actions. Despite suspending activities in March 2020, at UFPEL, this suspension did not last long. Seeking to reduce pedagogical damage, the university has taken a series of measures to guarantee the maintenance of a high quality and safe education, including the creation of the Support Center for Educational Technologies (NATE). This article aims to report on the experience of NATE / UFPEL, seeking to share the actions that were developed in order to support the adoption of emergency remote education at our university.

Keywords: Pandemic. Emergency remote education. Educational support Technologies. Experience. 
Com a pandemia do novo coronavírus (SARS-CoV-2') e a interrupção das atividades presenciais em praticamente todo o mundo, na área da Educação, as universidades tiveram que criar alternativas para dar continuidade às suas ações, em especial àquelas relacionadas ao ensino de graduação e pós-graduação. As atividades de pesquisa, sobretudo nesse período, não foram paralisadas, ao contrário, intensificaram-se, contribuindo bastante na compreensão do contexto e no combate à disseminação da COVID-19. Do mesmo modo, os programas de extensão mantiveram-se ativos de forma remota, sendo, inclusive, um importante mecanismo de interação social; de prestação de informações à sociedade; de manutenção das interações entre alunos e professores; de inserção de temáticas para discussões e reflexões, importantes para a compreensão da situação atual.

Em relação ao ensino, dados da UNESCO informaram que $91 \%$ dos estudantes no mundo tiveram as aulas interrompidas, decorrente do fechamento generalizado de instituições de ensino em 150 países (UNESCO, 2020 apud GUSSO et al. 2020). No Brasil, segundo dados do Ministério da Educação (MEC), em 21 de maio de 2020, das 69 universidades federais brasileiras, 56 estavam com as atividades acadêmicas de graduação totalmente suspensas e apenas 13 funcionavam parcial ou totalmente (VALENTE et al., 2020, p. 4).

Nesse contexto, a Universidade Federal de XXX (UFPEL), assim como as demais instituições de Ensino Superior do país em decorrência da crise sanitária, suspendeu, após 4 dias do início das aulas, todas as suas atividades por meio da Portaria $n^{\circ}$ 585, de 13 de março de 2020 (BRASIL, 2020b), visando a reduzir os riscos à saúde pública, não só da comunidade acadêmica, mas também da cidade e região. Ressalta-se que a referida universidade tem 50 anos de história e possuía até aquele momento aproximadamente 22,6 mil alunos e 2,6 mil servidores distribuídos em suas 22 unidades, totalizando 196 cursos, 4.329 disciplinas e 7.919 projetos de ensino, pesquisa e extensão universitária, o que gerava um fluxo importante de pessoas.

Gusso et al. (2020) destacam que no Brasil, cerca de um mês após ser declarada a emergência em saúde pública de importância nacional em decorrência da COVID-19, instituiu-se o Comitê Operativo de Emergência do Ministério da Educação (COE-MEC), que publicou, no início de março, a Portaria n 343/2020 (BRASIL, 2020a), alterada pelas Portarias $n^{\circ} 345 / 2020$ e $n^{\circ}$ 395/2020 (BRASIL, 2020a), e, no início de abril, a Medida Provisória 934/2020, autorizando a substituição das aulas presenciais pelas remotas, com a orientação de que estas fossem mediadas pelas tecnologias digitais de informação e comunicação.

Apesar das atividades terem sido suspensas em março na UFPEL, essa paralização não se estendeu por muito tempo. Buscando reduzir os danos pedagógicos, a instituição tomou uma série de medidas para garantir a manutenção de uma educação de qualidade e segura, mesmo optando, inicialmente, em não atender à recomendação da portaria supracitada. Ainda em março, foram criados o Comitê Interno para Acompanhamento da evolução da Pandemia, mais conhecido como Comitê Covid-19ii, e o Comitê Acadêmico, ambos da UFPEL. Dessa forma, iniciaram-se as discussões sobre a implementação de um calendário alternativo. A partir disso, originou-se o Comitê UFPEL Digital com o objetivo de constituir um espaço de formulação e 
materialidade de políticas institucionais voltadas à qualificação e ampliação das ferramentas e plataformas necessárias ao uso dos ambientes virtuais de aprendizagem no período de excepcionalidade, destacando-se a aquisição de equipamentos, atualização do sistema, organização de suporte, entre outras ações.

Dentre as primeiras providências implementadas pelo Comitê, destaca-se a criação, por parte da Pró-Reitoria de Gestão da Informação e Comunicação (PROGIC), de uma nova plataforma: o sistema e-AULA, ou Moodle das disciplinas, baseado na última versão do Moodle (DOUGIAMAS; TAYLOR, 2003) e totalmente integrado ao sistema de gestão acadêmica da universidade (Cobalto) e de webconferências, evitando a necessidade de solicitação para criar cursos, gerar novas senhas e até mesmo incluir professores e alunos.

No mês de abril, foi desenhada a proposta de um calendário alternativo a ser implantado em junho. A proposta do calendário alternativo, não obrigatório tanto para docentes quanto para estudantes, foi utilizada para desencadear o debate na comunidade acadêmica, inicialmente em uma reunião com os diretores das unidades acadêmicas e posteriormente junto a toda comunidade, exigindo um intenso diálogo entre os diversos setores da UFPEL: Pró-Reitoria de Ensino e suas coordenações; Coordenação de Pedagogia Universitária (CPU); Núcleo de Formação Docente (NUFOR); Coordenação de Registros Acadêmicos (CRA); Coordenação de Ensino e Currículo (CEC); Núcleo de Acessibilidade e inclusão (NAI); além do Comitê UFPEL Digital e das unidades acadêmicas.

Com a aprovação do calendário alternativo, o calendário 2020/1, que havia iniciado em março, foi suspenso para garantir a manutenção do vínculo dos alunos que por algum motivo não pudessem efetivar a matrícula nas atividades on-line. O calendário alternativo ofertou as aulas remotas - ministradas pelos professores por meio de ferramentas digitais - e condições mais flexíveis dos pré-requisitos para os estudantes. Além disso, a matrícula foi opcional, e a instituição garantiu ofertar novamente as disciplinas na retomada das atividades presenciais, ou seja, sem prejuízo aos alunos. Diante disso, as aulas virtuais foram iniciadas em 22 de junho e encerradas em 12 de setembro, com 12 semanas de duração.

Com o agravamento da pandemia, em julho foi determinado pelo Reitor, por meio da Portaria $n^{\circ} 1220$, de 30 de julho de 2020, a suspensão das atividades presenciais até 31 de dezembro de 2020 (BRASIL, 2020g). Como já havia sido publicada a Portaria MEC nº 544, de 16 de junho de 2020 que dispõe sobre a substituição das aulas presenciais por aulas em meios digitais enquanto durar a situação de pandemia da COVID-19 (BRASIL, 2020e), e o Parecer CNE/CP $n^{\circ} 11$, de 07 de julho de 2020, que dispõe sobre orientações educacionais para a realização de aulas e atividades pedagógicas presenciais e não presenciais no contexto da pandemia (BRASIL, 2020f), a UFPEL iniciou em agosto a elaboração de um novo calendário. Após longo processo de participação da comunidade acadêmica, foi aprovado junto ao Conselho Coordenador do Ensino, da Pesquisa e da Extensão (Cocepe), em 15 de setembro, o calendário acadêmico com o Ensino Remoto Emergencial (ERE), com início em 01 de outubro e término em 23 de dezembro de 2020.

A UFPEL criou e instituiu em junho de 2020, por meio da Portaria N 1011, o Núcleo de Apoio a Tecnologias Educacionais (NATE) (BRASIL, 2020d). Esse núcleo foi criado com o compromisso de dar suporte tecnológico ao ensino da universidade e ao processo de ensino-aprendizagem 
digital, visando a fortalecer a conexão entre docentes e acadêmicos no processo de construção do conhecimento científico e na gestão pedagógica.

O presente artigo tem por objetivo relatar a experiência do NATE da Universidade Federal de Pelotas ao longo desse processo do ERE, procurando compartilhar as ações que foram desenvolvidas para apoiar a adoção dessa modalidade na referida instituição. Os dados apresentados no presente relato de experiência são de domínio dos autores, os quais fazem parte da coordenação e equipe do Núcleo de Apoio a Tecnologias Educacionais desde que este foi criado. Nas seções a seguir, o trabalho pretende resgatar brevemente as ações para retomada do semestre letivo no contexto da pandemia nas universidades federais localizadas no Rio Grande do Sul; em seguida, descreve as ações desenvolvidas pelo NATE, bem como os resultados obtidos; por fim, apresenta as conclusões sobre essa experiência que certamente terá desdobramentos para o futuro do ensino na instituição.

\section{A EDUCAÇÃO SUPERIOR EM TEMPOS DE PANDEMIA}

As pesquisas e os relatos publicados sobre a Educação Superior em tempos de pandemia expressam a complexidade e os desafios envolvidos na retomada das aulas nas universidades em diferentes partes do mundo (ARRUDA, 2020). No Brasil, de norte a sul do país, docentes e estudantes foram surpreendidos pela necessidade de adaptar suas práticas em um exercício diário de enfrentamento dos obstáculos (ALBUQUERQUE; GONÇALVES; BANDEIRA, 2020; GOMES et al, 2020). Silva et al. (2020) apontaram que, apesar de as novas tecnologias da informação e comunicação estarem cada vez mais presentes em sala de aula por conta da Educação a Distância, ao analisar os currículos de formação de professores no estado do Rio de Janeiro, verificou-se que esses educadores não estavam preparados para articular metodologias de ensino e tecnologias. No cenário da COVID-19 e do isolamento social, docentes e alunos que, em sua maioria, não faziam uso das tecnologias digitais para o ensino e aprendizagem, viram-se obrigados a utilizá-las.

Adicionalmente, a necessidade de criar os meios para dar continuidade às ações amplificou a importância do uso das tecnologias digitais na educação, demandando tanto ações de suporte à comunidade acadêmica quanto à formação de docentes, produção de materiais de apoio e ao estreitamento dos canais de comunicação, etc. (ARRUDA, 2020).

Desde o início da pandemia, existiu uma grande preocupação da gestão da UFPEL em manter o diálogo com a comunidade. Nesse sentido, conforme destacado na introdução, muitas discussões ocorreram com a participação de todos os envolvidos nesse processo. Os principais objetivos dessas conversas eram definir práticas para mitigar os danos pedagógicos, reduzir os riscos à saúde pública e manter o vínculo com os alunos por meio de um ensino não presencial de excelência. A partir disso, muitas açõesiii foram efetuadas, desde prestar informação de qualidade à comunidade em geral a prestar serviços de apoio à comunidade acadêmica. Ressaltase que, antes da criação do NATE, foram realizadas diversas atividades de formação docente por intermédio da CPU.

Assim como a UFPEL, outras universidades no Estado do Rio Grande do Sul e no país procuraram soluções para dar prosseguimento às aulas, tendo em vista a falta de perspectivas na 
retomada das atividades presenciais, uma vez que a pandemia no Brasil continuava. No mês de maio de 2020, das 69 instituições federais de ensino existentes no país, somavam 56 aquelas que estavam com as aulas de graduação totalmente suspensas; em 17 de novembro de 2020, segundo dados do MEC, todas as instituições já haviam adotado as atividades de forma remota (BRASIL, 2020h).

Na próxima subseção, será apresentado um breve panorama sobre como ocorreu o prosseguimento das aulas nas universidades federais localizadas no Estado gaúcho.

\subsection{A retomada das aulas no contexto da pandemia nas universidades federais localizadas no Rio Grande do Sul}

Em um rápido levantamento de informações nos sites das universidades e de notícias sobre a retomada das atividades nas universidades gaúchas, verificou-se que houve um esforço significativo para a materialização de ações de ensino. Uma das saídas encontradas pelas instituições foi a implementação de calendários acadêmicos utilizando o Ensino Remoto Emergencial. Entende-se por ERE a adequação curricular temporária realizada pelas instituições como alternativa para que ocorram as atividades acadêmicas relacionadas às diversas disciplinas dos cursos, devido às circunstâncias de crise sanitária; a modalidade envolve o uso de soluções de ensino totalmente remotas, que de outra forma seriam ministradas presencialmente ou de forma híbrida (HODGES et al., 2020 apud VALENTE et al., 2020).

Figura 1 - Forma de funcionamento das universidades federais localizadas no RS, segundo dados do MEC em novembro de 2020

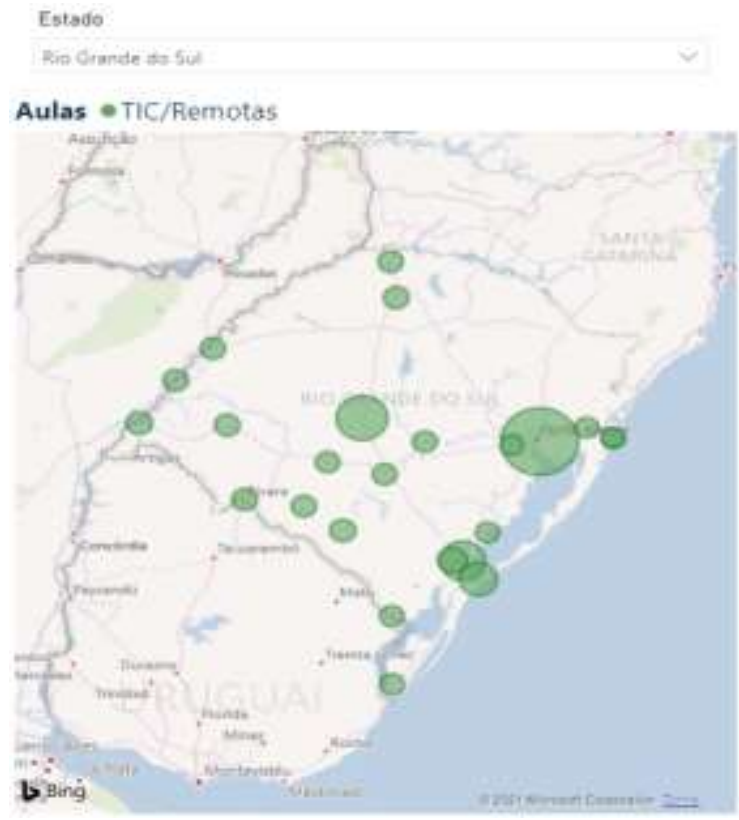

Fonte: Brasil (2020h).

No mês de novembro de 2020, das seis universidades federais existentes no Rio Grande do Sul, todas estavam funcionando por meio de atividades remotas, conforme pode ser observado 
na Figura 1, extraída do portal criado pelo MEC para monitorar o funcionamento e as principais ações das universidades, dos institutos federais, dos Centros Federais de Educação Tecnológica (Cefets) e do Colégio Pedro II durante a pandemia do novo coronavírus.

Destaca-se o esforço realizado pela Universidade Federal de Santa Maria (UFSM) que sem demora, em 17 de março, divulgou a Instrução Normativa N. 002/2020, regulamentando o Regime de Exercícios Domiciliares Especiais (REDE), não obrigatório (BRASIL, 2020c). Na cartilha do REDE, a instituição cita a pesquisa realizada sobre o regime implementado. Essa investigação, que contou com a cooperação de $32 \%$ do total dos estudantes e, destes, praticamente a metade (43\%) possuía cadastro de Benefício Socioeconômico, apontou que $86 \%$ dos respondentes optaram e conseguiram participar do REDE (UFSM, 2020b). Segundo consta no site da UFSM, o Núcleo de Tecnologia Educacional (NTE) (UFSM, 2020a) é o espaço responsável pela elaboração dos cursos - tanto daqueles a distância quanto dos semipresenciais - e projetos de educação mediados por tecnologias educacionais.

Nas demais instituições, o processo resultou na suspensão das atividades até a retomada do semestre letivo 2020/01. Segundo as informações disponibilizadas, a Universidade Federal do Rio Grande do Sul (UFRGS) retomou as aulas em 19 de agosto utilizando o Ensino Remoto Emergencial (UFRGS, 2020); a Universidade Federal do Pampa (Unipampa) deu seguimento às aulas em 08 de setembro por meio de Atividades de Ensino Remoto Emergenciais (AEREs) (UNIPAMPA, 2020b). Na Fundação Universidade de Rio Grande (FURG), ficou estabelecido no final de julho que o Período Emergencial 2020/1 teria início no dia 14 de setembro, permitindo a continuidade das atividades de ensino dos cursos de graduação e pós-graduação, mediadas pelas tecnologias de informação e com o uso de metodologias ativas (CADAVAL, 2020). Na Fundação Universidade Federal de Ciências da Saúde de Porto Alegre (UFCSPA) as atividades presenciais dos cursos de graduação e pós-graduação também foram suspensas, reiniciando em 3 de agosto de 2020 em caráter de Educação a Distância Emergencial (EaD-Em) (UFCSPA, 2020a).

A partir dessas informações, foi possível verificar que tanto a UFRGS quanto a FURG possuem uma Secretaria de Educação a Distância, responsável pelo suporte das atividades ligadas ao ERE. Já a Unipampa conta com uma Divisão de Educação a Distância e com o apoio do Grupo de Trabalho Novos Tempos no Ensino Superior, responsável pela construção do documento base para operacionalização das AEREs (UNIPAMPA, 2020a). Sobre a gestão da EaDEm na UFCSPA, a portaria consultada menciona o trabalho da Pró-reitoria de graduação e do Núcleo de Tecnologia da Informação (NTI) (UFCSPA, 2020b).

Na próxima seção, será apresentado o trabalho realizado pelo Núcleo de Apoio a Tecnologias Educacionais (NATE), criado pela UFPEL para dar suporte às ações de ensino durante a pandemia.

\subsection{A atuação do Núcleo de Apoio a Tecnologias Educacionais (NATE)}

Conforme foi destacado na introdução, o Núcleo de Apoio a Tecnologias Educacionais efetivou um importante papel colaborativo digital ao Ensino Superior relacionado à implementação do ensino remoto na universidade. 0 objetivo geral desse setor, desde sua 
criação, é a prestação de apoio técnico e pedagógico aos docentes e técnico-administrativos, bem como o auxílio aos estudantes no uso de plataformas e ferramentas digitais no ensino de graduação e de pós-graduação.

Além disso, os objetivos específicos do Núcleo são: dar suporte aos discentes no uso do Ambiente Virtual de Aprendizagem - Moodle; elaborar documentos orientadores e tutoriais; mediar a comunicação de conteúdos entre professor e aluno; auxiliar os professores dos cursos de graduação e pós-graduação na utilização das ferramentas institucionais para a prática docente no quesito suporte técnico da plataforma Moodle e das ferramentas de ensino virtual; auxiliar os professores da graduação e pós-graduação no suporte pedagógico, assim como apoiálos no desenvolvimento das atividades relativas dentro da plataforma.

Como será exposto no decorrer desta seção, tanto o objetivo geral como os objetivos específicos têm sido alcançados. Assim, para sua gestão e seu funcionamento, o NATE conta com uma coordenação compartilhada entre dois docentes da universidade e um conjunto de bolsistas - estudantes da universidade - selecionados mediante edital público. Dentre os principais critérios utilizados para a escolha desses alunos, destaca-se a experiência com o uso de computadores, de internet, da plataforma Moodle ou similar, de diferentes ferramentas virtuais e dos demais recursos de informática em especial em EaD. No total, foram convocados 30 bolsistas: 15 estudantes de graduação e 15 de pós-graduação, conforme ordem de classificação. Após, utilizou-se como estratégia de capacitação desses alunos a base dos questionamentos vindos dos docentes.

Além desses estudantes, o NATE possui um conselho formado por 12 professores de diferentes unidades da universidade, com os quais são realizadas reuniões periódicas para definição de prioridades, correção de rumos, apoio na realização das atividades previstas e definição das estratégias, assim como do planejamento do trabalho do Núcleo. A equipe de bolsistas participa de encontros virtuais regulares com a coordenação, e para alcançar as metas estabelecidas, formaram grupos para desempenhar trabalhos específicos: elaboração de guias, comunicação, atendimento, realização de pesquisas etc. O produto de cada um desses grupos de trabalho do Núcleo será descrito a seguir.

\subsubsection{Ações desenvolvidas}

Assim que o NATE foi estruturado, definiram-se as prioridades para atender as demandas do calendário alternativo que já havia sido iniciado. Assim como nas demais Instituições de Ensino Superior (IES), foram necessárias ações visando a auxiliar os professores, fornecendo suporte técnico e pedagógico durante esse período excepcional. O Núcleo enfrentou o desafio de, em um curto espaço de tempo, garantir suporte, atendimento, materiais e canais de apoio tanto para os docentes que ofertaram disciplinas ou qualquer outro componente curricular quanto para os estudantes matriculados durante os calendários implementados para o ERE.

A seguir, serão elencadas e descritas as principais ações desenvolvidas, de junho a dezembro de 2020, cujo propósito era o de manter a colaboração dos envolvidos, oferecer atendimento personalizado e, em especial, garantir o acesso a informações para capacitação do corpo docente da universidade frente às possibilidades e desafios do ensino on-line. Ressalta-se 
que as atividades foram definidas por meio de reuniões virtuais periódicas com o conselho e equipe, bem como pela troca de experiências e anseios no grupo do WhatsApp criado no início dos trabalhos.

\subsubsection{Criação da Rede NATE}

Uma das primeiras ações desenvolvidas foi a criação da Rede NATE/UFPEL, isto é, um espaço de formação, colaboração e trocas na plataforma Moodle, para atender as necessidades de suporte ao e-AULA durante o período previsto para o Calendário Alternativo. O objetivo da Rede é oferecer suporte e proporcionar a troca de informações entre os professores referente ao uso de tecnologias e metodologias educacionais. O foco estava centrado em apoiar o Ensino Remoto Emergencial por meio de espaços de formação e fóruns permanentes que permitissem a discussão, o esclarecimento de dúvidas e o compartilhamento de boas práticas e experiências relacionadas ao uso de tecnologias digitais no apoio aos processos de ensino e aprendizagem.

Para viabilizar a operação da Rede, o NATE utilizou outra plataforma no Moodle, criada pela PROGIC e idêntica ao e-AULA, chamada e-TREINAMENTO, voltada à realização de atividades de formação e ao treinamento de docentes. A primeira unidade a participar da Rede NATE foi o Centro de Engenharias (CEng/UFPEL), que atuou como protagonista, mobilizando docentes da própria unidade e de outras para compor a Rede e utilizar o e-TREINAMENTO como espaço de diálogo e formação.

A proposta inicial foi de que a gestão ocorresse de forma horizontal e de trabalho conjunto, por meio da formação de um Grupo Central e de Grupos de Colaboração para cada unidade da UFPEL. O Grupo Central foi formado pelos professores que integravam a coordenação e o conselho do NATE, pela equipe de bolsistas e por professores articuladores de diversas unidades.

Os professores articuladores atuaram na formação e animação dos grupos de colaboração e no apoio ao encaminhamento, junto ao NATE, das demandas não resolvidas. Os Grupos de Colaboração foram criados nas unidades que tiveram interesse em compor a Rede e contaram com professores representantes - articuladores - e também com os professores envolvidos nas ofertas do calendário alternativo e do calendário acadêmico 2020/01 em formato ERE. Cada unidade recebeu um espaço específico dentro e-TREINAMENTO destinado à troca de informações, ambientação com o e-AULA e articulação entre os docentes na utilização da plataforma.

\subsubsection{Criação de canais de comunicação com a comunidade acadêmica}

Para enfrentar os desafios impostos pelo distanciamento social, o NATE, no desenvolvimento de sua estratégia de ação, sempre soube que a comunicação teria um papel determinante. Por melhor que fossem os produtos e serviços desenvolvidos, se não houvesse a capacidade do núcleo de dar visibilidade e acessibilidade a isso, o esforço de toda a equipe se 
tornaria inócuo. Assim, apostou-se na organização de uma equipe de comunicação ampla e em uma parceria forte com a Coordenação de Comunicação Social (CCS) da universidade.

Os primeiros dois meses foram intensos, marcados por muitas reuniões e discussões nas quais se estabeleceu desde a identidade visual, método organizativo e estratégia de ação até o atendimento das questões pungentes que surgiam a todo momento, tendo em vista o calendário letivo que já encontrava-se em curso. Dessa forma, a proposta de comunicação do NATE ofereceu acesso aos espaços do núcleo a fim de promover discussões e ações em torno da educação online, mediante peças publicitárias, notícias e comunicação na busca ativa e nas mídias sociais, mitigando dúvidas e antecipando a solução de futuras questões.

Orientada pelos princípios da legalidade, dinamicidade, comunicação eficiente e da acessibilidade, a equipe em acordo com a CCS estabeleceu sua comunicação por meio dos canais oficiais da UFPEL - Youtube, Federal FM, Portal da UFPEL e Instagram - e dos próprios canais criados - Site e fanpage no Facebook.

Apesar disso, o Núcleo sempre se manteve fiel a sua estratégia de comunicação na qual todos são potencialmente comunicadores. Por isso, fomentou-se uma cultura de comunicação viral em que toda a equipe, o conselho e os parceiros estratégicos participaram da distribuição dos conteúdos e anúncio dos serviços do NATE. Destacam-se o desenvolvimento das seguintes ações: criação da fanpage e do site; elaboração de matérias e reportagens para tornar pública as ações do Núcleo no portal da universidade; criação de spots e conteúdos em áudio para a rádio Federal FM. Foi também nos primeiros meses de trabalho que foi desenvolvida a marca visual do Núcleo, que pode ser observada na figura 2 abaixo:

Figura 2. Logomarca do NATE/UFPEL

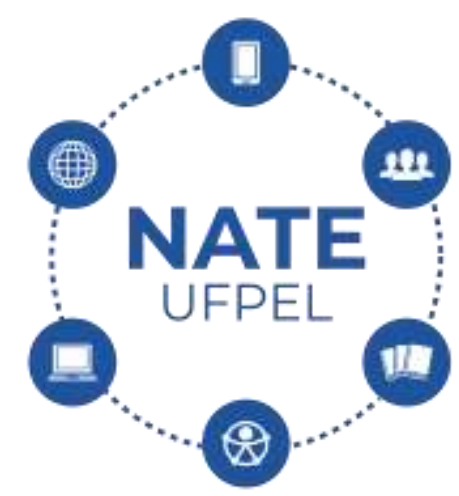

Fonte: NATE (2021).

O logo foi produzido na tentativa de descrever o que o NATE buscava e segue almejando com seu trabalho: a colaboração, a interatividade entre os espaços digitais acadêmicos, a valorização das pessoas que fazem e dão sentido a todo processo, a contribuição das ferramentas digitais nos processos de ensino e aprendizagem, bem como suas possibilidades de uso. Além disso, ilustra a centralidade da tarefa de prestar apoio pedagógico aos docentes e discentes da UFPEL no que tange às tecnologias digitais

Os elementos que compõem o símbolo do NATE dizem respeito à colaboração, interação, pedagogia, acessibilidade, às tecnologias e ao conhecimento científico. O conjunto faz menção 
ao cuidado e amparo com a comunidade acadêmica UFPEL e constrói um símbolo de sinergia e combinação dos esforços de cada pessoa envolvida no processo de ensino-aprendizagem, das ferramentas tecnológicas e do conhecimento. $O$ smartphone representa a noção da modalidade remota de ensino. O globo simboliza a conectividade, trazendo a ideia de que o conhecimento é um produto coletivo e produzido através da conexão entre as mentes de todo o planeta. As pessoas lado a lado enfatizam nossa opção pelo resgate dos sujeitos envolvidos e produtores do conhecimento na sua individualidade, mas como parte de uma comunidade. Os livros exprimem a importância de se estar atento a todo conhecimento instituído, para que seja possível produzir ciência, cultura e tecnologia com propriedade e legitimidade. O computador é o emblema da nova sala de aula, que ultrapassa o espaço convencional de ensino-aprendizagem e apresenta uma nova forma de encarar esse processo. A marca da acessibilidade expressa a busca pela inclusão de todas as pessoas indiferentemente de suas limitações, sem distinções.

Já o site do NATE ${ }^{\text {iv }}$ foi elaborado com o intuito de oferecer um ambiente para quem busca informações sobre o Ensino Remoto e como alternativa para fazer uma educação de qualidade nos tempos de distanciamento social. Na barra superior, consta quem são os membros do Núcleo e foi criado um atalho para os principais espaços do site. No topo, permanecem rodando imagens que anunciam e dão destaque às principais notícias, informações e aos materiais disponibilizados pelo NATE. No corpo do site, na parte central da página, encontra-se algumas notícias sobre ações e eventos relacionados com o ensino on-line em geral ou diretamente ligadas ao contexto das atividades do Núcleo e da UFPEL. Na barra lateral direita, existe um menu que dá acesso a materiais instrutivos, tutoriais, guias, FAQ e à fanpage. Nesse espaço, estão disponibilizados os materiais organizados pela equipe de curadoria, um tipo de suporte - que tem ganhado destaque nas metodologias de ensino on-line - voltado para as principais dúvidas identificadas na comunidade. Além disso, o site conta com um espaço onde o usuário pode ter acesso à playlist criada pelo NATE e que está dentro do canal da UFPEL no Youtubev. Por meio dessa playlist foram ofertados os links de acesso aos principais vídeos tutoriais de suporte ao e-AULA.

O site foi totalmente pensado e desenvolvido pela noção de promover uma curadoria, disponibilizando e facilitando o acesso dos usuários a diferentes tipos e formatos de informações que pudessem contribuir com uma compreensão globalizada do ensino on-line e suas possibilidades. Para o público interno da UFPEL, de forma mais exclusiva, destaca-se a sistematização de dúvidas frequentes, a prestação de serviços informativos e a disponibilização de materiais de apoio para discentes e docentes conduzirem da melhor forma possível suas disciplinas no ambiente virtual da UFPEL, o e-AULA.

Outra ação de comunicação desenvolvida foi o canal de atendimento. $O$ atendimento é um canal institucional de suporte no qual o docente pode ter suas dúvidas atendidas individualmente. Nesse espaço, a equipe de suporte do NATE oferece assistência individual aos professores e alunos da UFPEL. As solicitações são realizadas por meio de um link ${ }^{\mathrm{vi}}$, em que o demandante, servidor ou estudante, informa sua dúvida à equipe. Também foi criado um FAQ a partir das questões mais frequentes. Esse canal de atendimento foi produzido em meio ao desafio do calendário remoto, momento no qual a UFPEL padronizou, nas suas mais diferentes áreas, o atendimento em um canal exclusivo. Nesse canal, o usuário direciona sua área de atendimento, preenche seus dados pessoais, apresenta o seu problema ou dúvida. O pedido pode ser 
acompanhado tanto pelo site quanto pelo e-mail enviado pelo sistema. O NATE atende os tickets - solicitações de suporte, principalmente de professores e alunos - em três turnos, de segunda a sexta. Normalmente os tickets são respondidas no mesmo dia, exceto quando se trata de problemas de acesso ligados a questões tecnológicas ou de registro acadêmico. Nesses casos, são necessários testes e suporte de outras unidades como, por exemplo, da PROGIC ou da Coordenação de Registros Acadêmicos (CRA). As demandas que não podem ser resolvidas por meio de atendimento assíncrono - ou mesmo por uma questão de preferência do demandante, em geral docentes - podem ser sanadas em atendimento via webconferência nas chamadas "salas de atendimento", criadas para atendimento síncrono. Os atendimentos são marcados via ticket e o solicitante recebe os dados de acesso para a sala solicitada. Nesses encontros, há sempre dois bolsistas disponíveis para tirar dúvidas, dar suporte técnico e pedagógico aos docentes de uma forma mais acolhedora e com um feedback instantâneo.

Outra via de comunicação disponibilizada para apoio foi o e-mail institucional do Núcleo, utilizado especialmente antes da estruturação do canal de atendimento, da FAQ e das salas de atendimento. Além dessas ações, o NATE também se preocupou com a realização de atividades de formação, que serão relatadas a seguir.

\subsubsection{Ações de formação/capacitação para docentes e suporte para ambientação no Moodle}

Assim como em outras IES, parte do corpo docente da UFPEL não tinha familiaridade com o Moodle ou outros ambientes virtuais de aprendizagem e havia, mesmo antes da implementação do calendário alternativo, a necessidade de capacitar os educadores para atuarem em um contexto de ERE. Desse modo, o Núcleo desenvolveu o projeto Oficina Pedagógica do NATE, com o propósito de contribuir no desenvolvimento de habilidades e competências das práticas docentes. Em julho, foram realizados os primeiros cursos abertos para os professores de todas as unidades, com vagas limitadas e obtidas conforme a ordem de inscrição. A partir do mês de setembro, iniciou-se a oferta de oficinas de capacitação aos docentes de cada unidade da universidade. Essas oficinas consistiram em encontros síncronos, nos quais a equipe do NATE esclarecia dúvidas específicas.

Além das atividades de formação e a criação da Rede NATE, também foi disponibilizado, mediante solicitação dos professores, um espaço individual no e-TREINAMENTO, como um ambiente de prática no Moodle, voltado para o preparo das disciplinas, em especial, daqueles docentes que ainda não tinham utilizado os ambientes virtuais de aprendizagem.

O NATE também organizou uma oficina de formação para monitores virtuais, viabilizada por edital da Pró-Reitoria de Ensino (PRE) que ofereceu bolsa para 200 monitores que deveriam ser selecionados pelos docentes, além de permitir a escolha de mais 100 monitores voluntários.

Destaca-se que as ações de formação tiveram como foco o corpo docente e os monitores, uma vez que os estudantes foram perguntados sobre as demandas de formação em pesquisa realizada pelo NATE - relatada na subseção 2.2.1.5 - e a maioria respondeu não haver necessidade. Visando a atender estudantes e docentes em sua totalidade, o Núcleo providenciou a elaboração de materiais didáticos, cujo processo será relatado a seguir. 


\subsubsection{Produção de materiais didáticos/orientadores}

Além dos trabalhos de curadoria e criação de playlist citados anteriormente, o NATE também formou grupos específicos para elaboração de guias, um voltado para docentes ${ }^{\text {vii }}$ e outro para estudantes viii. Essas guias serviram de material de apoio, reunindo informações sobre o Moodle da UFPEL - e-AULA -, com o passo a passo das principais funções disponíveis ou necessárias de serem executadas dentro da plataforma. Paralelamente, com protagonismo do conselho, foram definidos os princípios do NATE ${ }^{\text {ix }}$, inspirados nas abordagens de educação propostas por Freire (2004), De La Taille (2006), Piaget (1965), Pimentel e Carvalho (2020), Silva (2016), Trivinho (2009) e Wills e Pegler (2016): 1- Acolhimento e Cuidado; 2- Interatividade e Cooperação; 3- Aprendizagem Significativa; 4- Reutilização de Conteúdos; 5- Autonomia; 6Criatividade.

Outro material, chamado Checklist ${ }^{x}$ do NATE, foi produzido a fim de apoiar os docentes na preparação das disciplinas no formato de ERE. Nesse documento, o Núcleo apresenta uma lista de tarefas básicas que devem ser realizadas sempre que um professor oferecer uma disciplina no e-AULA. Preocupada com a desistência ou evasão, a equipe do NATE elaborou também um manual de permanência ${ }^{x i}$, orientando como docentes e monitores podem verificar o acesso à plataforma dos estudantes matriculados em determinada disciplina, além de conter informações de como realizar uma busca ativa de estudantes infrequentes, promover o acolhimento e aumentar o engajamento desses alunos durante a pandemia. Visando estreitar o diálogo e verificar o andamento das ações desenvolvidas, o NATE junto a seu Conselho e a PRE, conduziu a realização de duas pesquisas, relatadas a seguir.

\subsubsection{Realização de pesquisas para avaliação dos calendários acadêmicos implementados durante a pandemia}

Passados dois meses da implementação do calendário alternativo, a coordenação do NATE propôs à PRE e ao Conselho a realização de uma pesquisa com estudantes e docentes, objetivando identificar como o Núcleo poderia contribuir para qualificar suas ações e agir em tempo hábil para prover alternativas de auxílio a professores e estudantes nesse período de calendário remoto, bem como para o semestre seguinte. Após a elaboração e a apreciação dos questionários pela equipe e conselho do NATE, foi solicitado junto à PROGIC/UFPEL os dados sobre as matrículas e ofertas de disciplinas constantes no sistema da universidade. Com isso, entre os dias 20 de agosto e 02 de setembro foi realizada a primeira pesquisa na comunidade acadêmica. Os questionários foram dirigidos especificamente para cada um dos sete grupos analisados: monitores virtuais; estudantes de graduação matriculados no calendário alternativo; estudantes de graduação não matriculados no calendário alternativo; estudantes de pósgraduação matriculados no calendário alternativo; estudantes de pós-graduação não matriculados no calendário alternativo; docentes de graduação e pós que ofertaram disciplinas no calendário alternativo; docentes de graduação e pós que não ofertaram disciplinas no calendário alternativo. 
Houve a participação expressiva de todos os convidados, com destaque para os docentes que ofertaram disciplinas no calendário alternativo: em 25/08/2020 todos os 842 docentes desse grupo receberam o questionário e até 01/09/2020, final do prazo para participação, tinham sido concluídos 481 questionários, o que representou $57,1 \%$ do número de convites enviados. Os resultados da pesquisa serviram de subsídios tanto para a organização do trabalho do NATE como para preparação do segundo calendário, que seria implementado em outubro.

Já no mês de novembro, o Núcleo realizou a segunda etapa da pesquisa, com o objetivo geral de avaliar as questões pertinentes ao calendário remoto iniciado em outubro, buscando a qualificação das ações de ensino não presencial. As questões e questionários foram elaborados pela equipe e conselho do NATE, mantendo praticamente as mesmas questões da primeira etapa e, com a colaboração da PROGIC/UFPEL, os convites foram enviados a partir das informações disponíveis no sistema da universidade.

Nessa etapa, participaram docentes com disciplinas no calendário remoto e estudantes de graduação e pós-graduação matriculados. Cerca de 4 mil estudantes e 800 docentes responderam ao questionário nessa fase. A pesquisa visou a avaliar as atividades remotas e a produzir um diagnóstico que possibilitasse sua gradual qualificação; além disso, contou com ampla divulgação dos canais do NATE e com o apoio da Coordenadoria de Comunicação Social da UFPEL. Todos os relatórios gerados, tanto da primeira quanto da segunda etapa, foram disponibilizados no site do NATE e utilizados como elementos de gestão. Os dados apurados subsidiarão o próximo calendário que iniciará em março de 2021.

\subsubsection{Promoção e participação em eventos virtuais}

Desde a retomada das aulas no contexto da pandemia, a coordenação do NATE tem participado de eventos virtuais a convite da reitoria, seja para esclarecimento do papel do Núcleo e suas atribuições em lives realizadas em junho e julho, seja para publicidade das ações praticadas em live no mês de outubro, todas listadas nos quadros 1 e 2.

Além disso, o NATE também produziu no mês de novembro uma live sobre Permanência, contando a participação do DCE da universidade; e organizou em dezembro juntamente com o Núcleo de Acolhimento e Apoio Tecnológico do Campus Visconde da Graça do Instituto Federal Sul Rio Grandense (NAAT CaVG/IFSul), Unirede e Proedu o evento Experiências no ensino não presencial: dimensões para o pós-pandemia, oferecendo para a comunidade e todos os interessados a experiência de troca e aprendizagem, buscando soluções a partir de diferentes cenários. Foram três dias de evento com temas sobre gestão e acolhimento; experiências europeias e brasileiras em recursos educacionais abertos; formas de operacionalização do ensino não presencial de acordo com as experiências da UFPEL e do CaVG/IFSul.

Na próxima seção, serão apresentados os resultados alcançados com o trabalho do NATE nesse período de excepcionalidade. 


\subsection{Resultados alcançados com as ações desenvolvidas pelo NATE}

Conforme abordado na seção anterior, o Núcleo desenvolveu em seis meses um conjunto importante de ações que de fato deram suporte para que os calendários acadêmicos propostos transcorressem com o menor número de problemas, dada a particularidade do período. Nos Quadros 1 e 2, demonstra-se a síntese das principais ações que foram planejadas a priori ou $a$ posteriori, bem como o seu desenvolvimento e os resultados alcançados.

Quadro 1: Quadro síntese das metas inicialmente planejadas, principais ações desenvolvidas e resultados alcançados pelo NATE/UFPEL de junho à dezembro de 2020

\begin{tabular}{|c|c|c|}
\hline Metas planejadas & Ações desenvolvidas & Resultados alcançados \\
\hline $\begin{array}{l}\text { Criação de espaços } \\
\text { colaborativos dentro da } \\
\text { plataforma Moodle }\end{array}$ & $\begin{array}{l}\text { Criação de espaços para as } \\
\text { unidades da universidade }\end{array}$ & $\begin{array}{l}28 \text { espaços criados no e- } \\
\text { TREINAMENTO }\end{array}$ \\
\hline \multirow{2}{*}{ Ações de formação docente } & $\begin{array}{l}\text { Organização e realização de } \\
\text { oficinas para docentes, } \\
\text { estudantes e monitores }\end{array}$ & $\begin{array}{l}20 \text { oficinas realizadas, envolvendo } \\
\text { cerca de } 1.000 \text { docentes }\end{array}$ \\
\hline & $\begin{array}{l}\text { Disponibilização de espaços de } \\
\text { prática para ambientação dos } \\
\text { docentes no Moodle }\end{array}$ & $\begin{array}{l}\text { Cerca de } 1.000 \text { ambientes de prática } \\
\text { disponibilizados e } 400 \text { docentes } \\
\text { atendidos }\end{array}$ \\
\hline \multirow{7}{*}{ Produção de materiais } & Elaboração do guia docente & 01 guia docente disponibilizado \\
\hline & Elaboração do guia estudantil & 01 guia estudantil disponibilizado \\
\hline & $\begin{array}{l}\text { Elaboração do manual de } \\
\text { permanência }\end{array}$ & $\begin{array}{l}01 \text { manual de permanência } \\
\text { disponibilizado }\end{array}$ \\
\hline & $\begin{array}{l}\text { Elaboração do manual de } \\
\text { formação de monitores }\end{array}$ & $\begin{array}{l}01 \text { manual de formação de monitores } \\
\text { elaborado }\end{array}$ \\
\hline & Elaboração da checklist do NATE & Checklist do NATE disponibilizado \\
\hline & Criação de vídeos e da playlist & 16 vídeos disponibilizados no site \\
\hline & Curadoria & 147 conteúdos organizados \\
\hline \multirow{5}{*}{$\begin{array}{l}\text { Criação de canais de } \\
\text { atendimento personalizado }\end{array}$} & $\begin{array}{l}\text { Criação do sistema de } \\
\text { atendimento com tickets }\end{array}$ & 1.523 tickets respondidos \\
\hline & Criação das salas de atendimento & $\begin{array}{l}08 \text { salas criadas e } 36 \text { atendimentos } \\
\text { prestados }\end{array}$ \\
\hline & Produção da FAQ & 33 perguntas e respostas prontas \\
\hline & Criação do e-mail institucional & Acompanhamento diário \\
\hline & Criação de site & Site com mais de 14.000 visualizações \\
\hline
\end{tabular}




\begin{tabular}{|l|l|l|}
\hline \multirow{4}{*}{$\begin{array}{l}\text { Criação de canais de } \\
\text { comunicação com a } \\
\text { comunidade }\end{array}$} & $\begin{array}{l}\text { Criação de fanpage com } \\
\text { postagens diárias }\end{array}$ & $\begin{array}{l}\text { Mais de } 3.000 \text { visualizações em } \\
\text { postagens estratégicas }\end{array}$ \\
\cline { 2 - 3 } & $\begin{array}{l}\text { Produção de materiais para o } \\
\text { portal da UFPEL }\end{array}$ & $\begin{array}{l}\text { Elaboração de } 20 \text { matérias e } 05 \\
\text { destaques }\end{array}$ \\
\cline { 2 - 3 } & $\begin{array}{l}\text { Produção de spots e conteúdos } \\
\text { em áudio para a rádio da UFPEL }\end{array}$ & $\begin{array}{l}02 \text { spots produzidos e 04 conteúdos } \\
\text { de cunho jornalístico disponibilizados }\end{array}$ \\
\hline
\end{tabular}

Fonte: Elaborado pelos autores a partir de dados da gestão do NATE/UFPEL (2021).

É preciso destacar que nem todas as ações relatadas haviam sido planejadas desde o início, muitas foram incorporadas ao planejamento à medida que novas demandas da comunidade surgiram, conforme se destaca no Quadro 2.

Quadro 2: Atividades posteriormente planejadas e executadas pelo NATE

\begin{tabular}{|c|c|c|}
\hline $\begin{array}{l}\text { Ações planejadas } a \\
\text { posteriori }\end{array}$ & Ações desenvolvidas & Resultados alcançados \\
\hline \multirow{2}{*}{$\begin{array}{l}\text { Realização de pesquisas } \\
\text { com a comunidade sobre o } \\
\text { andamento dos calendários } \\
\text { por meio do ERE }\end{array}$} & $\begin{array}{l}\text { Pesquisa de acompanhamento do calendário } \\
\text { alternativo }\end{array}$ & 7.531 respondentes \\
\hline & $\begin{array}{l}\text { Pesquisa de avaliação do calendário acadêmico } \\
\text { com ERE }\end{array}$ & 4.800 respondentes \\
\hline \multirow{7}{*}{$\begin{array}{l}\text { Realização e participação } \\
\text { em eventos e lives }\end{array}$} & $\begin{array}{c}\text { Apresentação do NATE em live da UFPEL } \\
\text { https://I.UFPEL.edu.br/jxe7ur }\end{array}$ & 2,4 mil visualizações \\
\hline & $\begin{array}{l}\text { Orientações do NATE em live da UFPEL } \\
\text { https://I.UFPEL.edu.br/m654vo }\end{array}$ & 2 mil visualizações \\
\hline & $\begin{array}{l}\text { Apresentação do trabalho do NATE em live da } \\
\text { UFPEL https://I.UFPEL.edu.br/izaaai }\end{array}$ & 2 mil visualizações \\
\hline & $\begin{array}{l}\text { Live sobre Permanência } \\
\text { https://I.UFPEL.edu.br/bae08s }\end{array}$ & 1,3 mil visualizações \\
\hline & $\begin{array}{l}\text { Live sobre Gestão e Acolhimento } \\
\text { https://I.UFPEL.edu.br/k6y0l0 }\end{array}$ & 208 visualizações \\
\hline & $\begin{array}{c}\text { Live sobre Experiências da Operacionalização } \\
\text { do Ensino não presencial } \\
\text { https://I.UFPEL.edu.br/oko0r3 }\end{array}$ & 143 visualizações \\
\hline & $\begin{array}{c}\text { Live sobre a Experiência europeia e brasileira } \\
\text { em Recursos Educacionais Abertos } \\
\text { https://I.UFPEL.edu.br/a315f8 }\end{array}$ & 347 visualizações \\
\hline
\end{tabular}

Fonte: Elaborado pelos autores a partir de dados da gestão do NATE/UFPEL (2021).

Dentre as ações desenvolvidas, destacamos o canal de atendimento que, nesse período de pandemia e impossibilidade de atendimento presencial, mostrou-se um espaço ágil e eficiente 
de comunicação. O NATE realizou mais de mil atendimentos relacionados ao Moodle da UFPEL Ambiente e-AULA - na graduação e pós-graduação. No gráfico abaixo, elaborado segundo as informações obtidas pela barra de pesquisa do atendimento realizado pelo Núcleo, é possível visualizar a sistematização dos principais atendimentos de caráter técnico-pedagógicos realizados até o dia 23 de dezembro.

\section{Gráfico 1: Sistematização dos atendimentos prestados pelo NATE através do sistema de atendimento da UFPEL no período de julho a dezembro de 2020}

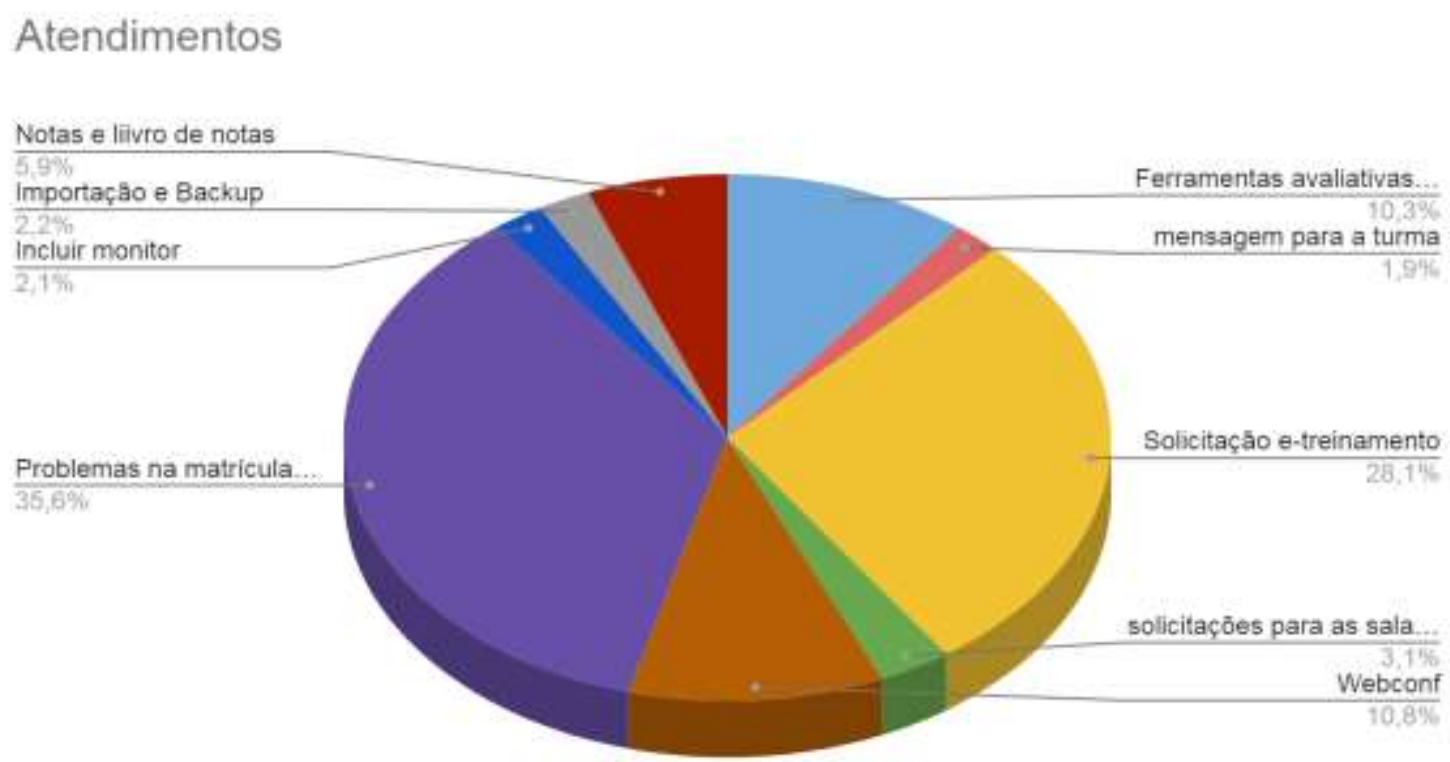

Fonte: NATE/UFPEL a partir dos dados coletados pela equipe do canal de atendimento (2021).

Como se pode observar no gráfico, um problema técnico recorrente foi o Problema na matrícula. A caminhada de estabelecimento dos recursos para o Ensino Remoto passou por vários desafios, e uma funcionalidade que alavancou a qualidade do e-AULA foi sua vinculação à plataforma Acadêmica da UFPEL, o Cobalto. Nesse percurso alguns ajustes foram necessários e contabilizou-se um total de 420 atendimentos ligados à matrícula.

A dúvida comum nos atendimentos foi relacionada ao uso e exploração das funcionalidades do e-AULA na oferta das disciplinas. As solicitações no e-TREINAMENTO contabilizaram 331 aberturas de tickets, representando que mais de mil disciplinas foram abertas em ambientes de treinamento. Conforme destacado anteriormente, nessa modalidade de atendimento, disciplinas hipotéticas foram abertas na plataforma Moodle - espaço eTREINAMENTO - ambiente no qual os professores responsáveis por disciplinas, com apoio de membros do NATE, desenvolveram suas habilidades no ambiente virtual de ensinoaprendizagem, o e-AULA.

O gráfico demonstra ainda que: $35,6 \%$ dos chamados foram sobre o erro "shibboleth" que foi corrigido pelo CRA; $28,1 \%$ referentes à solicitação de entrada nos ambientes de prática no eTREINAMENTO; 10,8\% sobre webconferência, sendo demandas sobre gravação (33), incluir 
participantes externos (20), problemas técnicos (40) e dúvidas e dificuldades para acessar (19); as dúvidas sobre as ferramentas avaliativas e de recursos totalizaram 122 solicitações, o que correspondeu a 10,3\%, sendo 120 referentes a dúvidas e problemas das funcionalidades de atividades, como tarefas, questionários e wiki e apenas 02 de recursos como URL e arquivo; 5,9\% dos atendimentos foram sobre dúvidas e problemas sobre o livro de notas; $3,1 \%$, relacionados às salas de atendimento; 2,2\% referentes a dúvidas e problemas sobre importação e backup; 2,1\% corresponderam a dúvidas e problemas para incluir um monitor nos atendimentos; e 1,9\% foram em relação à bug no envio de mensagem às turmas.

Destaca-se também o alcance dos canais de comunicação. A experiência do NATE nas redes sociais foi marcada pela distribuição dos conteúdos e pelos anúncios das atividades por meio da qq no Facebook. Com conteúdos produzidos de forma exclusiva para essa rede, pensando no público alvo, métricas e demais especificidades, manteve-se uma assiduidade de três postagens diárias. O site do NATE, pensado para ser em primeiro lugar um provedor de conteúdos, possui uma funcionalidade ampla, abrigando notícias, destaques - promovidos por intermédio de artes abrigadas em um plugin específico que garante mais visibilidade - , além de um menu lateral que dá acesso a espaços como o da Curadoria e FAQ.

Conforme ressaltado no Quadro 1, o site tem sido bastante acessado. No Gráfico 2, abaixo, pode-se observar que a maioria das visualizações ocorreu nos meses de setembro e outubro de 2020.

Gráfico 2: Métrica dos registros de visualizações no site do NATE/UFPEL, de julho de 2020 a janeiro de 2021.

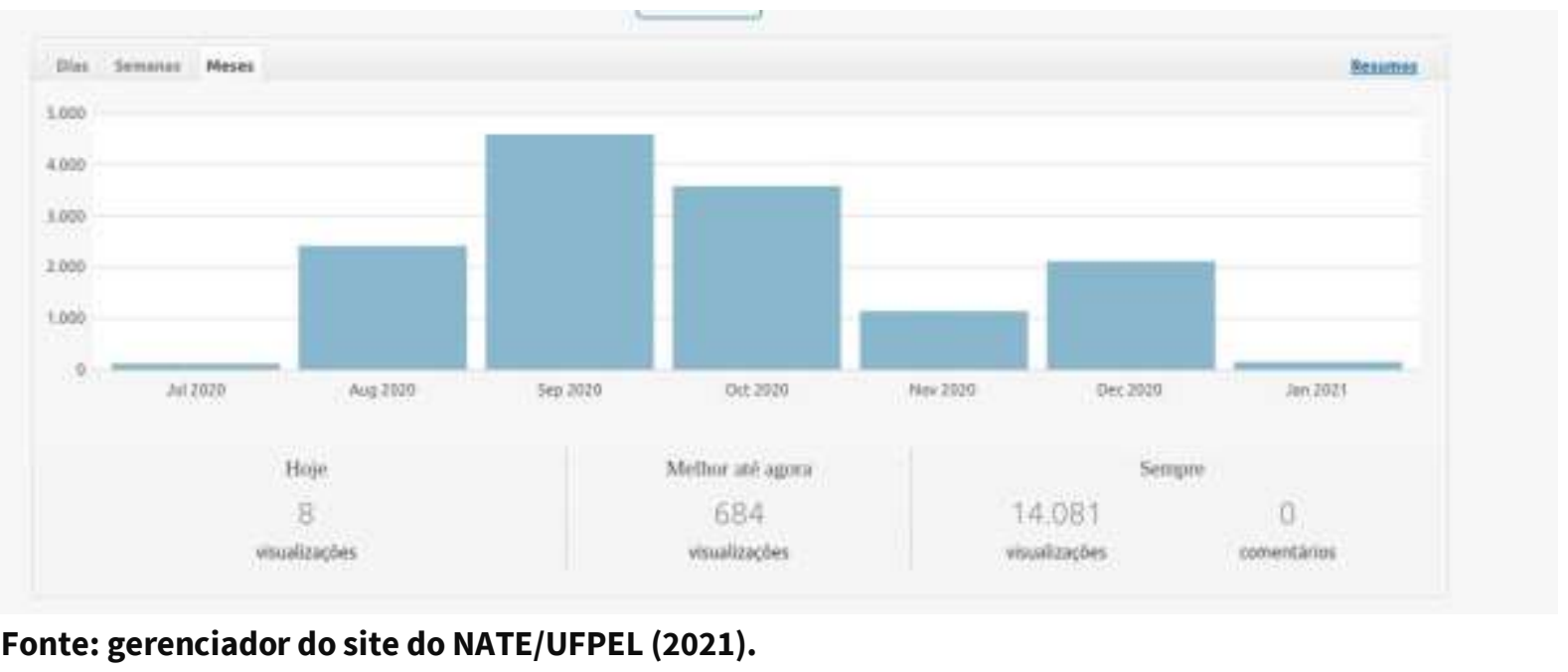

Já na Figura 3, pode-se observar as visualizações de cada post, com destaque para o grande número na postagem sobre os resultados preliminares da pesquisa realizada pelo NATE sobre o calendário acadêmico com o Ensino Remoto, seguida da postagem sobre perguntas frequentes (FAQ) e a playlist de vídeos. 
Figura 3. Número de visualizações dos principais posts do site do NATE desde a sua criação

\begin{tabular}{|c|c|c|}
\hline \multicolumn{3}{|l|}{$\begin{array}{l}\text { Principais posts para tudo dias, até 2021-01-13 (Resumido) } \\
7 \text { Dias } \mid \underline{30 \text { Dias } \mid \text { Trimestre } \mid \text { Ano } \mid \text { Sempre }}\end{array}$} \\
\hline \multicolumn{3}{|l|}{ Todo o Tempo } \\
\hline Titulo & \multicolumn{2}{|c|}{ Visualizaçöes } \\
\hline Página inicial/ Arquivos & 亚 & 4.957 \\
\hline Dados Preliminares da Pesquisa sobre o Calendário Acadêmico com Ensino remoto & 哪 & 1.206 \\
\hline Perguntas Freq. (FAQ) & 盤 & 1.116 \\
\hline Playlist de videos & 期 & 1.023 \\
\hline Guia Estudantil & 政 & 822 \\
\hline Curadoria & 船 & 614 \\
\hline CONFIRA OS RESULTADOS PRELIMINARES DA PESQUISA SOBRE O CALENDÁRIO REMOTO & 瞒 & 482 \\
\hline orientacoesparaEstudantes & 期 & 384 \\
\hline Suporte & 政 & 383 \\
\hline Quem Somos & 哪 & 322 \\
\hline Perguntas Freq. (FAQ) -teste & 曋 & 268 \\
\hline Ambientes Virtuais de Aprendizagem & 期 & 252 \\
\hline Contato & 形南 & 241 \\
\hline Bolsistas & 阷 & 197 \\
\hline As dúvidas surgem no caminho! & 洋 & 188 \\
\hline Coordenadores & 唯 & 158 \\
\hline Principios e Serviços do Nate & 期 & 139 \\
\hline AVALIAÇÃO DO CALENDÁRIO ACADÉMICO COM ENSINO REMOTO EMERGENCIAL ACONTECERÁ ENTRE 23 E $30 \ldots$ & 啨 & 137 \\
\hline Consetho & 湔 & 130 \\
\hline Audios & 期 & 120 \\
\hline Membros & 期 & 88 \\
\hline O ENSINO REMOTO TAMBÉM PODE INCLUIR & 哪 & 87 \\
\hline AS PRINCIPAIS ATIVIDADES DE SUPORTE AOS DOCENTES DESENVOLVIDAS PELO NATE-UFPEl & 期 & 77 \\
\hline Curadoria Digital & 期 & 72 \\
\hline CHECKLIST DO NATE & 政 & 64 \\
\hline Materiais de Apoio & ofli & 47 \\
\hline Novo canal de atendimento & 船 & 47 \\
\hline Seja Bem-vindo ao site do NATE! & 期 & 41 \\
\hline Produçâo de Videoaulas & 晋 & 41 \\
\hline Direitos Autorais e de Imagem & ofli & 39 \\
\hline
\end{tabular}

Fonte: gerenciador do site do NATE/UFPEL (2021).

Há de se registrar ainda outros resultados não apresentados, difíceis de serem mensurados, especialmente aqueles envolvendo as parcerias, redes e vínculos estabelecidos ou estreitados, mesmo em uma situação de distanciamento social e relacionamento limitado ao espaço virtual. São diversos os relatos de agradecimento e reconhecimento ao trabalho realizado pelo NATE no período, o que transcende as metas estabelecidas de antemão. 
A crise sanitária vivenciada no mundo, em decorrência da pandemia do novo coronavírus, tem demonstrado de forma cada vez mais explícita que a normalidade que se acreditava existir, de fato, não era normal, na medida em que a sociedade global já vivia em crise: econômica, social, ambiental, de civilidade (SANTOS, 2020). Essa crise se somou às que já existiam e afetou a todos, diferentemente das anteriores que de forma mais direta e imediata atingia a grupos específicos, em especial, os grupos vulneráveis da sociedade. Tal constatação não significa que se deve minimizar o momento no qual se vive, ao contrário, é um alerta para o fato de que, além de cuidar da saúde pessoal e tomar todas as medidas recomendadas para evitar o contágio, é preciso cuidar do outro. Talvez o cuidado, a atenção, a solidariedade, a cooperação, o sentido coletivo sejam as questões que possam mobilizar a todos no presente e no futuro.

Nessa perspectiva e com esses princípios, inicia-se as discussões sobre o retorno das atividades de ensino na UFPEL, utilizando os recursos e ferramentas tecnológicas, com o propósito primeiro de aproximar as pessoas e não frustrar projetos de vida. A criação de espaços, setores, núcleos, ferramentas, aquisição de equipamentos, adequação de procedimentos e processos foram necessários e urgentes, mas, ao mesmo tempo, foram pensados, analisados, planejados no sentido de manter, ainda que em situação de excepcionalidade, a qualidade acadêmica.

A implementação de ações de ensino durante a pandemia trouxe muitos desafios e, também, aprendizados. O NATE, que era apenas uma semente, foi ganhando corpo e acabou, em um curto período de tempo, desenvolvendo um conjunto de ações relatadas nas seções desse trabalho. Contudo, cabe destacar que esse tipo de unidade, bastante especializada, não se operacionaliza de forma automática a partir de uma portaria. Com a formalização do Núcleo, iniciou-se um processo árduo de estruturação "em pleno voo", pois era preciso dar suporte aos professores para ministrarem suas aulas no calendário remoto, havendo apenas 14 dias de intervalo entre a portaria de constituição do NATE e o início das aulas.

Os momentos iniciais de ação do Núcleo foram muito intensos, pois as dúvidas e ansiedades dos professores eram inúmeras e das mais variadas possíveis. Um dos fatores que causou muita ansiedade foi a nova plataforma, constituída a partir da versão atualizada do Moodle, batizada de e-AULA. Por ser totalmente integrada ao Sistema de Gestão Acadêmica (Cobalto) da UFPEL, gerou dúvidas até mesmo para os professores que já se consideravam confortáveis ou seguros na utilização do AVA. Iniciou-se, então, um período de muito trabalho para dirimir as dúvidas, em especial dos professores, e que acabou formando uma base de conhecimento para o sistema de atendimento, cuja implantação via software foi decisiva para qualificar o suporte aos docentes e discentes durante todo esse período.

As pesquisas realizadas mostraram que o trabalho do NATE foi bem aceito e que, apesar de todas as dificuldades, o processo de ensino-aprendizagem ocorreu durante a pandemia. Entre os desafios e aprendizados, ressalta-se ainda a criação e manutenção de uma rede de parcerias, de uma dinâmica de reuniões virtuais periódicas e a troca de experiências e ansiedades nos grupos de WhatsApp criados no início das atividades, tanto com o conselho quanto com os bolsistas. Tal processo, mesmo que totalmente virtual e com integrantes que até então não se conheciam, foi 
fundamental para a definição das prioridades, correção de rumos e desenvolvimento das ações previstas.

Sem dúvidas, a experiência com o Ensino Remoto e o trabalho do NATE oportunizaram a identificação de demandas importantes para implantação de ações de Ensino Híbrido necessárias no futuro e que permitirão avançar técnica e pedagogicamente no ensino on-line. Nesse sentido, a produção de materiais didáticos e as atividades de formação foram importantes para a qualificação do corpo docente da universidade.

Apesar dos problemas trazidos pela pandemia, a experiência com o Ensino Remoto Emergencial permitiu que algumas barreiras referentes ao ensino não presencial fossem quebradas. Em um momento tão sombrio, foi possível criar alternativas para manter o ensino na UFPEL por meio do Calendário Alternativo e posteriormente pelo Calendário Acadêmico com o ERE. Essas ações possibilitaram aproximar a comunidade acadêmica, construindo novas formas de ensinar, novas perspectivas e quebrando paradigmas. Esse foi um período de aprendizado coletivo e fica a certeza de que a universidade cumpriu o seu papel.

\section{REFERÊNCIAS}

ALBUQUERQUE, A.; GONÇALVES, T. O.; BANDEIRA, M. C. S. A formação inicial de professores: os impactos do ensino remoto em contexto de pandemia na região Amazônica. EmRede: Revista de Educação a Distância, Porto Alegre, v. 7, n. 2, p. 102-123, nov. 2020. Disponível em: https://www.aunirede.org.br/revista/index.php/emrede/article/view/639. Acesso em: 29 dez. 2020.

ARRUDA, E. P. Educação remota emergencial: elementos para políticas públicas na educação brasileira em tempos de Covid-19. Em Rede:Revista de Educação a Distância, Porto Alegre, v. 7, n. 1, p. 257-275, 2020. Disponível em: https://www.aunirede.org.br/revista/index.php/emrede/article/view/621. Acesso em: 08 set. 2020.

BRASIL. Ministério da Educação. Coronavírus: ações do MEC em resposta à pandemia da COVID-19. 2020h. Disponível em: http://portal.mec.gov.br/coronavirus/. Acesso em: 04 jan. 2021.

BRASIL. Ministério da Educação. Gabinete do Ministro. Portaria n. 544, de 16 de junho de 2020. Dispõe sobre a substituição de aulas presenciais por aulas em meios digitais enquanto durar a situação de pandemia do Novo Coronavírus - COVID-19. Diário Oficial da União: seção 1, Brasília, DF, n. 114, p. 62, 17 jun. 2020e. Disponível em: https://www.in.gov.br/en/web/dou/-/portaria-n-544-de-16-de-junho-de-2020261924872. Acesso em: 29 dez. 2020.

BRASIL. Ministério da Educação. Parecer CNE/CP nº 11, de 07 de julho de 2020. Orientações Educacionais para a Realização de Aulas e Atividades Pedagógicas Presenciais e Não Presenciais no contexto da Pandemia. Diário Oficial da União: seção 1, Brasília, DF, p. 57, 03 ago. 2020f. Disponível em: http://portal.mec.gov.br/docman/julho-2020-pdf/148391-pcp011-20/file. Acesso em: 29 dez. 2020.

BRASIL. Ministério da Educação. Portaria n. 343, de 17 de março de 2020. Dispõe sobre a substituição de aulas presenciais por aulas em meios digitais enquanto durar a situação de pandemia do Novo Coronavírus - COVID-19. Diário Oficial da União: seção 1, Brasília, DF, n. 53, p. 39, 18 mar. 2020a. Disponível em: http://www.in.gov.br/en/web/dou/-/portaria-n-343-de-17-de-marco-de-2020-248564376. Acesso em: 29 dez. 2020.

BRASIL. Ministério da Educação. Universidade Federal de Pelotas. Portaria n 585, de 13 de março de 2020. Pelotas, RS, 2020b. Disponível em: 
https://sei.UFPEL.edu.br/sei/publicacoes/controlador_publicacoes.php?acao=publicacao_visualizar\&id_ documento=1033172\&id_orgao_publicacao=0. Acesso em: 29 dez. 2020.

BRASIL. Ministério da Educação. Universidade Federal de Pelotas. Portaria $\mathbf{N}^{\circ} \mathbf{1 0 1 1}$, de 08 de Junho de 2020. Criação do Núcleo de Apoio às Tecnologias Educacionais (NATE). Pelotas: RS, 2020d. Disponível em: https://sei.UFPEL.edu.br/sei/publicacoes/controlador_publicacoes.php?acao= publicacao_visualizar\&id_documento=1108701\&id_orgao_publicacao=0. Acesso em: $29 \mathrm{dez} .2020$.

BRASIL. Ministério da Educação. Universidade Federal de Santa Maria. Pró-Reitoria De Graduação. Instrução Normativa N. 02/2020/PROGRAD de 17 de março de 2020. Regula o Regime de Exercícios Domiciliares Especiais (REDE) e o funcionamento da Pró Reitoria de Graduação (PROGRAD) e Departamento de Registro e Controle Acadêmico (DERCA) durante a Suspensão das Atividades Acadêmicas e Administrativas em face da Pandemia COVID-19. Santa Maria: UFSM, 2020c. Disponível em: https://www.ufsm.br/app/uploads/sites/342/2020/03/IN-002-2020-PROGRAD-UFSM.pdf. Acesso em: 05 jan. 2021.

BRASIL. Ministério da Educação. Universidade Federal de XXX. Portaria № 1220, de 30 de Julho de 2020. Pelotas: RS, 2020g. Disponível em:

https://sei.UFPEL.edu.br/sei/publicacoes/controlador_publicacoes.php?acao=publicacao_visualizar\&id_ documento=1154660\&id_orgao_publicacao=0. Acesso em: 29 dez. 2020.

CADAVAL, F. FURG reinicia as atividades de ensino para período emergencial de forma remota. 2020. Disponível em: https://www.furg.br/noticias/noticias-institucional/furg-reinicia-as-atividades-de-ensinopara-periodo-emergencial-de-forma-remota. Acesso em: 05 jan. 2021.

DE LA TAILLE, Y. Moral e ética: dimensões intelectuais e afetivas. Porto Alegre: Artmed, 2006.

DOUGIAMAS, M.; TAYLOR, P. Moodle: Using learning communities to create an open source course management system. In: EdMedia+ Innovate Learning. Association for the Advancement of Computing in Education (AACE). Waynesville: AACE, 2003. Disponível em:

https://www.learntechlib.org/primary/p/13739/. Acesso em: 29 dez. 2020.

FREIRE, P. Pedagogia da autonomia: saberes necessários a prática educativa. São Paulo: Paz e Terra, 2004.

FUNDAÇÃO UNIVERSIDADE FEDERAL DE CIÊNCIAS DA SAÚDE DE PORTO ALEGRE (UFCSPA). Portaria 29/2020/Reitoria, de 3 de julho de 2020. Dispõe sobre os procedimentos e rotinas nas atividades acadêmicas e administrativas, visando o reinício das aulas do calendário acadêmico de 2020 dos cursos de graduação, dos estágios obrigatórios e dos programas de pós-graduação da Fundação Universidade Federal de Ciências da Saúde de Porto Alegre - UFCSPA - em caráter de Educação a Distância Emergencial. Porto Alegre: UFCSPA, 2020a. Disponível em: https://www.ufcspa.edu.br/sobre-aufcspa/normas/reitoria/905-portaria-29-2020-reitoria-de-3-de-julho-de-2020. Acesso em: 05 jan. 2021.

FUNDAÇÃO UNIVERSIDADE FEDERAL DE CIÊNCIAS DA SAÚDE DE PORTO ALEGRE (UFCSPA). Portaria 27/2020/Prograd, de 8 de julho de 2020. Dispõe sobre as rotinas nas atividades acadêmicas, considerando a declaração de pandemia mundial pela Organização Mundial de Saúde em 11 de março de 2020, bem como a Resolução Conjunta CONSUN-CONSEPE $n^{\circ}$ 17/2020/CONSUN, de 2 de julho de 2020, visando o reinício das aulas do calendário acadêmico de 2020 dos cursos de graduação, dos estágios obrigatórios e dos programas de pós-graduação da Fundação Universidade Federal de Ciências da Saúde de Porto Alegre - UFCSPA - em caráter de Educação a Distância Emergencial. Porto Alegre: UFCSPA, 2020b. Disponível em: https://www.ufcspa.edu.br/sobre-a-ufcspa/normas/prograd/1175-portaria-272020-prograd-de-8-de-julho-de-2020 Acesso em: 05 jan. 2021. 
GOMES, V. T. S. et al. A Pandemia da Covid-19: Repercussões do Ensino Remoto na Formação Médica.

Revista Brasileira de Educação Médica, Brasília, DF, v. 44, n. 4, e114, 2020. Disponível em:

http://www.scielo.br/scielo.php?script=sci_arttext\&pid=S0100-55022020000400602\&lng=en\&nrm=iso.

Acesso em: 22 fev. 2021.

GUSSO, H. L. et al. Ensino superior em tempos de pandemia: diretrizes à gestão universitária. Educação e

Sociedade, Campinas, v. 41, e238957, 2020. Disponível em:

http://www.scielo.br/scielo.php?script=sci_arttext\&pid=S0101-73302020000100802\&lng=en\&nrm=iso.

Acesso em: 04 jan. 2021.

PIAGET, J. Estudos sociológicos. Rio de Janeiro: Forense, 1965.

PIMENTEL, M.; CARVALHO, F. S. P. Princípios da Educação Online: para sua aula não ficar massiva nem maçante!. 2020. Disponível em: http://horizontes.sbc.org.br/index.php/2020/05/23/principios-educacaoonline. Acesso em: 27 jul. 2020.

SANTOS, B. S. Coronavírus: tudo que é sólido desmancha no ar. 2020. Disponível em:

https://blogdaboitempo.com.br/2020/04/02/coronavirus-tudo-o-que-e-solido-desmancha-no-ar/. Acesso em: 27 jul. 2020.

SILVA, J. S. et al. Letramento Digital: desafios à formação docente. EmRede: Revista de Educação a Distância, Porto Alegre, v. 7, n. 2, p. 15-29, nov. 2020. Disponível em:

https://www.aunirede.org.br/revista/index.php/emrede/article/view/613. Acesso em: 27 jul. 2020.

SILVA, M. Sala de Aula Interativa. Rio de Janeiro: Quartet, 2006.

TRIVINHO, E. (Org.). A cibercultura e seu espelho. São Paulo: ABCiber; Instituto Itaú Cultural, 2009.

Disponível em: https://abciber.org.br/publicacoes/livro1/. Acesso em: 27 jul. 2020.

UNIVERSIDADE FEDERAL DE SANTA MARIA (UFSM). Cartilha/Resumo REDE: Regime de Exercícios Domiciliares Especiais (REDE). Santa Maria: UFSM, 2020b. Disponível em:

https://www.ufsm.br/app/uploads/sites/421/2020/09/Cartilha-Resumo-REDE.pdf. Acesso em: 05 jan. 2021.

UNIVERSIDADE FEDERAL DE SANTA MARIA (UFSM). Núcleo de Tecnologia Educacional (NTE). 2020a. Disponível em: https://repositorio.ufsm.br/handle/1/11912. Acesso em: 05 jan. 2021.

UNIVERSIDADE FEDERAL DO PAMPA (UNIPAMPA). Aprovadas as diretrizes operacionais para o Ensino Remoto Emergencial. 2020b. Disponível em:

https://sites.unipampa.edu.br/prograd/2020/08/19/aprovadas-as-diretrizes-operacionais-para-o-ensinoremoto-emergencial/. Acesso em: 05 jan. 2021.

UNIVERSIDADE FEDERAL DO PAMPA (UNIPAMPA). Unipampa debate diretrizes para o Ensino Remoto Emergencial durante o Consuni. 2020a. Disponível em: https://unipampa.edu.br/portal/unipampadebate-diretrizes-para-o-ensino-remoto-emergencial-durante-o-consuni. Acesso em: 05 jan. 2021.

UNIVERSIDADE FEDERAL DO RIO GRANDE DO SUL (UFRGS). Aulas do Ensino Remoto Emergencial começam nesta quarta-feira. 2020. Disponível em: https://www.ufrgs.br/coronavirus/base/aulas-doensino-remoto-emergencial-comecam-nesta-quarta-feira/. Acesso em: 05 jan. 2021.

VALENTE, G. S. C. et al. Remote teaching in the face of the demands of the pandemic context: Reflections on teaching practice. Research, Society and Development, v. 9, n. 9, p.e843998153, 2020. Disponível em: https://rsdjournal.org/index.php/rsd/article/view/8153. Acesso em: 05 jan. 2021. 
WILLS, S.; PEGLER, C. A Deeper Understanding of Reuse: Learning Designs, Activities, Resources and Their Contexts. Journal of Interactive Media in Education, v. 2016, n. 1, Article 10, 2016. Disponível em: https://eric.ed.gov/?id=EJ1093932. Acesso em: 27 jul. 2020.

' Para mais informações sobre a pandemia no Brasil ver https://www.dw.com/pt-br/cronologia-da-covid19-no-brasil/g-52930927

ii Saiba mais em https://ccs2.ufpel.edu.br/wp/tag/comite-interno-da-covid-19/

iii Saiba mais em https://wp.ufpel.edu.br/covid19/acoes_da_ufpel/

iv Conheça o site em https://wp.ufpel.edu.br/nate/

${ }^{\vee}$ Conheça a playlist em https://www.youtube.com/user/UFPELoficial/playlists

vi Conheça o sistema de atendimento em https://atendimento.ufpel.edu.br/

vii Disponível em https://wp.ufpel.edu.br/nate/files/2020/09/Guia-Docente.pdf

viii Disponível em https://wp.ufpel.edu.br/nate/files/2020/09/GUIA_ESTUDANTIL.pdf

${ }^{\text {ix }}$ Conheça os princípios do NATE em https://wp.ufpel.edu.br/nate/files/2020/09/Principios-e-servicos-doNATE.pdf

x Disponível em https://wp.ufpel.edu.br/nate/files/2020/09/checklist-para-disciplinas-no-e-AULA.pdf

xi Disponível em https://wp.ufpel.edu.br/nate/files/2020/09/Manual-do-resgate.pdf 